\title{
Direitos Humanos, Novas Tecnologias e Resiliência do Direito
}

\begin{abstract}
Luis Gustavo Gomes Flores
Professor do Programa de Graduação e Pós-graduação em Direito (Mestrado em Direitos Humanos da Universidade Regional do Noroeste do Estado do Rio Grande do Sul - Unijuí). Pós-doutor, doutor e mestre pelo Programa de Pós-Graduação em Direito da Universidade do Vale do Rio dos Sinos - Unisinos. Graduado no curso de Direito da Universidade de Santa Cruz do Sul - Unisc (2003/2). Professor titular do Projeto Institucional: Desenvolvimento Humano, Transformações Sociais e Resiliência do Direito. Pesquisador do Grupo de Pesquisa Teoria do Direito - Unisinos, São Leopoldo/RS. Integrante do grupo de pesquisa Desarmamento Humanitário: abordagem política, ligado ao curso de Relações Internacionais e Integração da Universidade Federal da Integração Latino-Americana - Unila, Foz do Iguaçu/PR. Integrante do grupo de pesquisa Direitos Humanos, Meio Ambiente e Novos Direitos (Projeto Novas Tecnologias, Responsabilidade e Direitos Humanos) - Programa de Mestrado em Direitos Humanos da Unijuí. Advogado inscrito sob o número OAB/RS 60.076. Foi coordenador do curso de Direito do Ceulm/Ulbra, Manaus (2011), Conselheiro Editorial da Revista da Associação Brasileira de Pesquisadores em Sociologia do Direito - ABraSD, Editor da Revista jurídica Metajuris.gustavogf7@gmail.com
\end{abstract}

O presente artigo tem como tema de estudo a importância da ideia de resiliência nas reflexões jurídicas para pensar os direitos humanos diante dos desafios trazidos pelas Novas Tecnologias Digitais em uma Sociedade Complexa. Para tanto, buscou-se responder ao problema de pesquisa que indaga: Qual a contribuição que a ideia de resiliência pode dar para pensar os direitos humanos diante de uma sociedade complexa, fortemente marcada pelos desafios trazidos pelas Novas Tecnologias Digitais? Trata-se de um trabalho crítico reflexivo que tem como objetivo geral demonstrar a necessidade que se tem no Direito de pensar novas possibilidades de observação que levem em consideração a importância da inovação no Direito para enfrentar a complexidade social, fortemente marcada pelo avanço das Novas Tecnologias Digitais. Para tanto utilizou-se o método sistêmico construtivista, por meio de pesquisa bibliográfica. Tem-se como resultado a possibilidade de observação de novas perspectivas a serem consideradas, a partir de um potencial ainda não explorado suficientemente, mas levando em conta as contribuições da Resiliência do Direito abrem-se novas possibilidades para tanto.

Palavras-chave: Direitos humanos. Novas Tecnologias. Resiliência do Direito.

\section{HUMAN RIGHTS, NEW TECHNOLOGIES AND RESILIENCE OF LAW}

\section{ABSTRACT}

The purpose of this article is to study the importance of the idea of Resilience in legal reflections to think about Human Rights in the face of the challenges brought by the New Digital Technologies in a Complex Society. To that end, we sought to answer the research question that asks: what contribution can the idea of resilience give to thinking about Human Rights in the face of a complex society, strongly marked by the challenges brought by the New Digital Technologies? It is a critical reflective work whose general objective is to demonstrate the need in the Right to think new possibilities of observation that takes into account the importance of innovation in the Law to face the social complexity, strongly marked by the advance of the New Digital Technologies. For that, a constructivist systemic method was used, through bibliographic research. It has resulted in the possibility of observing new perspectives to be considered, from a potential still not sufficiently explored, but considering the contributions of the Resilience of the Right opens new possibilities for so much.

Keywords: Human rights. New technologies. Resilience of Law.

1 Introdução. 2 Reconstrução da Epistemologia Jurídica: condições para compreender os Direitos Humanos na Sociedade Complexa. 3 Direitos Humanos e os Desafios das Novas Tecnologias Digitais. 4 Resiliência do Direito e as Contribuições aos Direitos Humanos Diante dos desafios das Novas Tecnologias Digitais. 5 Conclusão. 6 Referências. 


\section{Introdução}

No contexto da sociedade atual a dinâmica, a incerteza e a multiplicidade de possibilidades de sentidos sugere um ambiente social altamente complexo. Daí que se pode pensar a ideia de Sociedade Complexa. ${ }^{1}$ Essa complexidade identificada com a modernidade, por meio de certa diferenciação funcional (LUHMANN, 2007, p. 589), é amplificada na atualidade pelo avanço das Novas Tecnologias Digitais. Essa tendência possibilitou a intensificação das comunicações em uma dimensão global e instantânea, provocando inúmeras mudanças nas relações sociais.

Essa conjuntura complexa tende a problematizar profundamente as estruturas tradicionais do Direito (também de muitas outras áreas de conhecimento), resultando em problemas de ineficácia e exclusão social. Muitas possibilidades de exclusão impactam na realização dos direitos humanos, agravando a o problema da ineficácia do Direito em um círculo vicioso.

Além, no entanto, de essa conjuntura social ser um grande desafio, também revela-se um campo fértil para o aprendizado e aprimoramento das reflexões jurídicas. Nas formas de sociedades anteriores as mudanças sociais ocorriam de maneira mais lenta. ${ }^{2}$ Havia maior espaço para previsões sobre o que poderia eventualmente acontecer no futuro, e qual a preparação necessária. Atualmente as expectativas na sociedade estão voltadas a uma dinâmica que exige respostas rápidas. Essa dinâmica social complexa envolve a todos, produzindo certa inclusão inevitável (em certa medida até forçada). Essa inclusão exige dois elementos básicos: esforço de adaptação e tecnologia. Um ambiente repleto de incertezas e contingências. A não adequação a essa dinâmica social contemporânea corresponde o risco de exclusão, defasagem ou descontextualização. Esse contexto social para o qual o Direito precisa apresentar respostas é também o mesmo que coloca em destaque suas fragilidades diante da complexidade social, como sua morosidade crônica, principalmente com certas insuficiências epistemológicas.

Entre a sociedade complexa e uma operacionalização jurídica predominantemente dogmática emerge o risco de ineficácia e descontextualização das respostas que o Direito apresenta às demandas sociais.

Apesar das dificuldades, as Novas Tecnologias Digitais reconfiguram as relações sociais, revelando grande potencial, tanto para desencadear efeitos benéficos como efeitos nocivos aos direitos humanos da sociedade. É justamente essa ambiguidade que abre espaço para novas reflexões voltadas a reexaminar a eficácia do Direito (em especial dos direitos humanos) no contexto social.

Com disposição para enfrentar essa complexidade interessa sugerir uma reflexão que tem como tema a importância da resiliência como proposta reflexiva para o Direito responder aos desafios atuais, em especial os direitos humanos diante das Novas Tecnologias Digitais e da Sociedade Complexa. Para tanto, busca-se responder ao problema de pesquisa que indaga: Qual a contribuição que a ideia de resiliência pode dar para pensar os direitos humanos dian-

Pode-se compreender aqui a ideia de Sociedade Complexa uma forma de sociedade altamente dinâmica, contingente e caracterizada por múltiplas possibilidades de sentidos diferentes.

2 Faz-se referências às formas de sociedade segmentária (LUHMANN, 2007, p. 502) e de sociedade estratificada (LUHMANN, 2007, p. 589). 
te de uma sociedade complexa, fortemente marcada pelos desafios trazidos pelas Novas Tecnologias Digitais? Trata-se de um trabalho crítico reflexivo com o objetivo geral de demonstrar a necessidade no Direito de pensar novas possibilidades de observação que considerem a importância da inovação no Direito para enfrentar os atuais desafios sociais, fortemente marcados pelo avanço das Novas Tecnologias Digitais.

O presente trabalho será desenvolvido em três pontos: no primeiro desenvolveu-se uma reflexão sobre as condições epistemológicas necessárias para o Direito construir uma observação adequada ao contexto de uma sociedade complexa. No segundo ponto observa-se alguns aspectos das mudanças sociais desencadeadas pelo avanço das Novas Tecnologias Digitais, potencializando a complexidade social e revelando o contraste entre perspectivas do sistema jurídico e a dinâmica do ambiente social que colocam em evidência as fragilidades jurídicas na realização dos direitos humanos. No terceiro ponto foi acentuada a importância de pensar a mudança, tanto na sociedade como no Direito, e o necessário aprimoramento das reflexões e sua operacionalização. Significa dizer que o Direito precisa ser resiliente para enfrentar seus (novos e antigos) desafios.

Para tanto adotou-se o método sistêmico construtivista, por meio de pesquisa bibliográfica. Uma investigação balizada por certas categorias teóricas que possibilitam uma visão complexa da sociedade, bem como a disposição para superar determinadas posturas e pressupostos dogmáticos. Uma provocação que sugere profundas mudanças na forma de observação (reflexão), organização e operacionalização do Direito, para que este seja capaz de apresentar, progressivamente, respostas cada vez mais satisfatórias para a sociedade como um todo.

\section{Reconstrução da Epistemologia Jurílica: condições para compreender os Direitos Humanos na Sociedade Complexa}

Inicialmente interessa recuperar um tema que desde a Grécia Antiga até os dias atuais tem sido motivo de muitas reflexões: a capacidade de observação do mundo. Trata-se de um tema-chave que pode ser utilizado como ponto de partida para se compreender o que está acontecendo na sociedade. Desde a alegoria da Caverna de Platão (1949), aos maiores avanços da Física na atualidade, persegue-se certa preocupação com o aprimoramento da capacidade de observação. Como no documentário Janela da Alma, produzido por João Jardim e Walter Carvalho (2001), não se trata de pensar essa questão simplesmente como um ato de enxergar ${ }^{3}$ que se realiza objetivamente com os olhos. Não se observa com as janelas, mas sim através delas. Isso sugere uma reflexão sobre a forma de construção da realidade. ${ }^{4} \mathrm{Um}$ processo compreensivo que é desenvolvido por um observador a partir de determinada re-

\footnotetext{
3 Trata-se de um documentário dirigido e produzido por João Jardim com codireção de Walter Carvalho cujo título é Janela da Alma e sugere uma reflexão sobre múltiplas formas de observar o mundo e por sua vez constituir uma noção de realidade através da qual cada um também se autoconstitui.

4 É claro que a própria concepção de realidade é altamente complexa. Falamos de forma genérica, utilizando uma linguagem comum, em realidade do nosso dia a dia, do que já aconteceu, de um processo geofísico do qual fazemos parte, do que é possível criar. De alguma forma elaboramos uma condição de sentido que nos permite uma compreensão contingente da realidade que podemos observar e representar simbolicamente, contudo, por exemplo, estudos desenvolvidos pela Física quântica revelam um mundo de infinitas possibilidades, em que a realidade é uma construção interna, produzida por meio de uma rede complexa de significações, fruto da capacidade de observação.
} 
presentação do mundo, que de certa maneira indica uma forma de construção da realidade (MATURANA, 2000, p. 61). Isso também ocorre no sistema do Direito. A exposição de fatos em uma petição inicial, em uma contestação ou mesmo em cada interpretação, envolve observações que significam certa construção da realidade, elaborada da perspectiva do sistema do Direito (LUHMANN, 2005, p. 89).

Basicamente se poderá observar perspectivas conservadoras ou não conservadoras. Em diversos momentos será possível constatar a insuficiência de perspectivas conservadoras, contudo convém considerar que a existência e manutenção de certo conservadorismo nem sempre ocorre em razão de uma incapacidade de observação do contexto social. Muitas vezes são sustentadas (até retoricamente) propositalmente em razão de algum interesse específico (velado ou explícito), como conservação de alguma forma de controle na produção do sentido jurídico. Às vezes uma postura dogmática favorece a manutenção e a justificação jurídica de certos interesses.

O Direito carece de uma revisão epistemológica que possibilite desenvolver reflexões para melhor contribuir para a sua evolução (LUHMANN, 2005, p. 331) como um todo. Por isso é tão relevante repensar as condições necessárias para o aprimoramento da epistemologia jurídica.

Ao longo da História, em diversas áreas do saber, inclusive no Direito, as heranças epistemológicas da modernidade já deram provas de sua insuficiência para pensar a complexidade da sociedade atual. Apesar da existência de inúmeras críticas sobre a racionalidade moderna, por parte de diversos autores, nas mais variadas perspectivas de observação, o peso da razão moderna ainda exerce grande influência na cultura jurídica ocidental.

No âmbito do Direito a matriz dominante na modernidade foi o normativismo jurídico (ROCHA, 2003b, p. 185). Adequado à sua época, dando respostas para as demandas de um determinando momento histórico, emergiu como uma grande contribuição para um desenvolvimento do Direito. A sociedade, contudo, passou a se tornar mais complexa com o passar do tempo, assumindo contornos diferentes daqueles em que o normativismo jurídico foi forjado.

Uma cultura jurídica forjada em longa prática de um Direito Corrente ${ }^{5}$ que privilegiou o aspecto da operacionalização (FERRAZ JR, 2011, p. 18) contribuiu muito para a consolidação de uma epistemologia moderna no âmbito jurídico. Isso resultou em uma grande simplificação do Direito, por meio da acentuação de aspectos técnicos, de "complexificações" burocráticas e na produção de conhecimentos jurídicos fragmentados, reducionistas e compartimentalizados. Essa forma de pensar o Direito é reconhecida como uma Dogmática Jurídica (ROCHA, 2003b, p. 195), uma forma de compreender o Direito que, por um lado, permite a sua operacionalização, mas por outro tende a gerar o risco de uma operacionalização jurídica excessivamente conservadora.

Nessa perspectiva a observação jurídica é empobrecida por uma ocultação dos aspectos multidimensionais do mundo e a incapacidade de perceber essa própria ocultação.

\footnotetext{
Direito Corrente é considerado um Direito que se operacionaliza predominantemente a partir da programação condicional, mas pressupõe uma postura de abertura para o próprio aprimoramento. É utilizado para diferenciar uma prática jurídica corrente, em que a dogmática busca garantir a operacionalização do Direito mantendo certa disposição de aprimoramento de uma pratica jurídica que acentua excessivamente uma perspectiva mais conservadora e por isso é chamada pejorativamente de dogmática jurídica
} 


\section{Hiceitos \\ Humanos e}

Democracia

Poder-se-ia falar em uma espécie de ponto cego (FOERSTER, 1996, p. 59-74) na observação jurídica, um obstáculo interno (BACHELARD, 2011, p. 15-16) para acessar a complexidade que se revela como uma crise generalizada na epistemologia do Direito. Em razão da complexidade desse obstáculo uma estratégia que se pode adotar para identificar as insuficiências jurídicas é a observação de certos contrastes entre a dinâmica das demandas sociais e a dinâmica de operacionalização do Direito (ROCHA, 2003b, p. 197).

O contexto social contemporâneo constitui o que chamamos (didaticamente) aqui de complexidade real ${ }^{6}$ (extremamente dinâmica e contingente), contudo as leituras que se pode fazer dessa complexidade real, a partir do Direito, são leituras parciais e correspondem a uma "realidade parcial - construída pelo Direito". ${ }^{7}$ Essa complexidade social é reestruturada a partir da perspectiva e do sentido jurídico. Não é aleatório que numa perspectiva sistêmica do Direito e da sociedade aquele pode ser compreendido como um sistema parcial desta.

Dessa forma, a concepção de realidade observada/construída a partir da perspectiva do Direito dependerá proporcionalmente da respectiva capacidade de observação e consequentemente das suas próprias estruturas internas que poderão permitir a ele desenvolver uma observação ampla e aberta, ou restrita e reducionista.

Aqui a epistemologia terá grande importância no que diz respeito aos rumos que a operacionalização do Direito pode tomar. Interessa pensar uma epistemologia que permita que a realidade construída pelo Direito esteja o mais compatível e coerente possível com a complexidade (real) da sociedade. Isso significa ser capaz de considerar riscos, paradoxos e contingências (CLAM, 2006, p. 73-74).

Se a "realidade" depende da maneira como se observa a sociedade, a própria compreensão dos problemas ou demandas que dela emergem também são dependentes de uma construção (de certa observação), que em alguma medida é específica (MATURANA; VARELA, 2001). Logo, uma observação/construção da realidade equivocada ou insuficiente poderá comprometer a qualidade e a eficácia das respostas que, a partir do Direito, serão elaboradas para as demandas sociais. ${ }^{8}$

Para escapar dessa problemática é importante compreender alguns aspectos necessários para se buscar certo aprimoramento da capacidade de observação do Direito. Nesse sentido, algumas das principais condições para o aprimoramento da observação, como forma de sofisticação da epistemologia jurídica, podem ser consideradas como sendo: 1) a compreensão de pertencimento a uma conjuntura complexa e interdependente; 2) flexibilidade; 3) disposição para considerar múltiplos saberes; 4) capacidade de conservação e mudança; 5)

\footnotetext{
Para fins didáticos busca-se com essa expressão indicar a diferença entre o que se consegue observar da complexidade, constituindo uma perspectiva de realidade, e o que, independente da incapacidade de um observador conseguir observar, existe numa dimensão da complexidade mais ampla, que se convencionou chamar aqui de real.

Significa que a construção da "realidade", de certa forma, é uma construção parcial, específica e seletiva de uma dimensão mais ampla que pode ser indicada aqui como "o real".

8 Uma observação reducionista, simplista ou excessivamente conservadora poderá, da mesma forma, resultar em respostas jurídicas reducionista, simplista ou excessivamente conservadora. Considerando que a sociedade é constituída de diferentes sistemas sociais parciais, apresentar uma resposta para "a sociedade" significa apresentar uma resposta que esteja, de alguma forma, voltada para múltiplas perspectivas de saberes, representadas também na forma de sistemas sociais.
} 
disposição de questionar permanentemente os pressupostos jurídicos e a 6) capacidade de enfrentar encadeamentos diversos e complexos de significações sociais, buscando explorar ao máximo as novas possibilidades. ${ }^{9}$

1) Quanto à compreensão de pertencimento a uma conjuntura complexa e interdependente, consiste no entendimento de que o Direito constitui uma das estruturas sociais e está imerso em um ambiente compreendido por diversos âmbitos de conhecimentos, chamados também de sistemas sociais, cada qual com sua função e forma específica de se auto-organizar (LUHMANN, 2016, p. 29-30). ${ }^{10}$

2) Quanto à flexibilidade, esta pode ser importante para tensionar os aspectos conservadores do Direito que, pelo fato de se mostrarem insuficientes diante do contexto social complexo, contrastam com aspectos mais desenvolvidos de outras áreas ou não alcançam efetivamente a satisfação das demandas sociais. A flexibilidade pode ser importante para um primeiro movimento de superação de aspectos dogmáticos, mas depende de certa reflexividade para que não seja utilizada como um recurso para a manipulações do Direito (FLORES; ROCHA, 2016, p. 55).

3) Sobre a disposição para considerar múltiplos saberes, mostra-se importante na medida em que permite observar como são elaboradas as concepções (de mundo) na perspectiva da dogmática jurídica em comparação com outras áreas de conhecimento que podem dar relevantes contribuições (e demandas) para as reflexões jurídicas (NICOLESCU, 2005, p. 5253).

4) Quanto à capacidade de conservação e mudança, diz respeito à importância de saber observar de forma não dogmática que a "conservação" possui um papel importante para garantir a manutenção das aquisições evolutivas, principalmente no que diz respeito aos direitos humanos e fundamentais, como conquistas sociais e que ao mesmo tempo, para ela se manter em um mundo dinâmico é preciso ser equacionada à ideia de "mudança" (ROCHA, 2003b, p. 199). É a mudança que terá condições de possibilitar a atualização, o aprendizado e a evolução do Direito. Não se trata, contudo, de considerar a mudança simplesmente porque se está imerso numa sociedade em constante movimento, mas considerar a importância de produzir mudanças evolutivas, tendo em conta um processo reflexivo de seleção do que deve ser mudado e o que deve ser mantido (OST, 1999, p. 195). A conservação permite garantir avanços já realizados e a mudança proporciona o aprendizado necessário para superar obstáculos e possibilitar uma realização evolutiva do Direito.

5) A disposição de questionar permanentemente os pressupostos jurídicos indica uma reflexão sobre observação de aspectos a serem aprimorados, bem como mecanismos eficientes para compreender e diagnosticar a sociedade e suas demandas. Isso permite pensar em um processo de monitoramento constante da evolução jurídica, considerando a sua atuação diante desse contexto (LUHMANN, 2005, p. 304).

\footnotetext{
Tudo isso pode ser facilmente compreendido por meio da ideia de autopoiése (MATURANA; VARELA, 1997).

${ }^{10}$ Essa perspectiva já sugere que o referencial teórico para a presente reflexão conta com uma grande contribuição da perspectiva da Teoria dos Sistemas Sociais (Autopoiéticos) de Niklas Luhmann.
} 
6) Nessa perspectiva, a capacidade de enfrentar encadeamentos complexos de significações e buscar explorar novas possibilidades diz respeito à necessidade de repensar o Direito considerando a importância das possibilidades de contribuições de certa perspectiva transdisciplinar (NICOLESCU, 2005, p. 54-55). Na medida em que o Direito tem a função de elaborar respostas aos problemas de uma sociedade complexa, constituída por inúmeros sistemas sociais, ele precisa levar em conta a multiplicidade de perspectivas possíveis.

Essas são as condições necessárias de aprimoramento epistemológico que possibilitam o desenvolvimento da observação jurídica e consequentemente da sua operacionalização. Isso é cada vez mais necessário e urgente para enfrentar a complexidade da sociedade contemporânea, incrementada pelas Novas Tecnologias Digitais. Os constantes avanços tecnológicos que fomentam a complexidade social desencadeiam inúmeras transformações que são marcadas pela grande velocidade de acontecimentos, que também são recheados de imprevisibilidade, incertezas e riscos. Tudo isso tende a dificultar qualquer operacionalização do Direito que siga uma orientação excessivamente dogmática.

Isso pressupõe não somente a concepção do Direito como um sistema dinâmico e evolutivo, mas também que ele está imerso em um ambiente igualmente dinâmico e complexo, o que exige uma constante reflexão envolvendo a articulação interdependente entre sistema e ambiente (LUHMANN, 2016, p. 38).

A importância de pensar uma renovação da epistemologia jurídica experimentando certa abertura para a transdisciplinaridade implica repensar também a cultura jurídica de forma crítica. Isso exige uma profunda avaliação das posturas tradicionalmente contidas no Direito que dificultam a realização dos direitos humanos ou mesmo contribuem para recorrentes violações desses direitos que se cristalizam de forma imperceptível no cotidiano por meio da naturalização de pequenas (mas significativas) castrações das relações humanas.

Por essas razões os direitos humanos precisam ser revisitados de forma crítica, por uma epistemologia jurídica sofisticada, a fim de serem considerados numa perspectiva complexa, sobretudo a partir das implicações causadas pelo avanço das Novas Tecnologias Digitais.

\section{Direitos Humanos e os Desafios das Novas Tecnologias Digitais}

O que se sabe inicialmente é que se pode considerar uma diversidade de consequências, tanto benéficas como nocivas para o desenvolvimento humano em sociedade. Por "Novas Tecnologias Digitais" compreende-se aqui os avanços no âmbito da informática que possibilitaram a produção de uma comunicação digital, por meio da web, com a conexão de computadores em âmbito global a partir do espaço virtual da Internet (LEVY, 2007, p. 43-44). Essas tecnologias estão praticamente em todo o âmbito social, transcendendo fronteiras tradicionais do espaço-tempo. Estão presentes desde os smartphones que são carregados no bolso por bilhões de usuários, até os mais sofisticados laboratórios, estudos e equipamentos de ponta sobre Inteligência Artificial (BARONE; BOESING, 2015). Apesar dessa ampla expansão as Novas Tecnologias Digitais, em si, não podem ser consideradas ruins ou boas. . Essa avaliação depende de como serão utilizadas e quais serão as consequências de sua inserção na sociedade. 
As mudanças sociais desencadeadas pelas Novas Tecnologias Digitais e eventuais repercussões em relação aos direitos humanos são grandes desafios que o Direito deve enfrentar na sociedade atual.

Para melhor compreender a complexidade que orbita as relações entre Novas Tecnologias Digitais, transformações sociais e direitos humanos, é importante considerar a concepção de sociedade de Niklas Luhmann. Nessa perspectiva a sociedade moderna ganha contornos de uma sociedade funcionalmente diferenciada e complexa, que pode ser compreendida como um sistema social que se auto-organiza a partir das comunicações que produz. Por isso para Luhmann a sociedade é comunicação (LUHMANN, 2007, p. 18). Esta se constitui em um elemento fundamental para a realização e conexão social. É por meio dela que as relações e decisões ocorrem conectando uma coletividade. Tudo o que acontece dizendo respeito ao social acontece mediante a comunicação. ${ }^{11}$ Por isso a sociedade é tão afetada pelas Novas Tecnologias Digitais. Elas transformam drasticamente as inúmeras relações comunicativas, desencadeando as seguintes mudanças:

a) Potencializaram o alcance das ressonâncias comunicativas no espaço-tempo para além de dimensões individuais. Dessa forma, abre-se a possibilidade para a vivência de estar simultaneamente próximo e distante, sozinho e acompanhado, etc.

Aparelhos tecnológicos passaram a substituir amplamente a presença pessoal, tanto nas relações de trabalho quanto nas relações pessoais. Isto pressupõe simultaneamente riscos e benefícios. Pode significar um potencial para desenvolver lucidez e conhecimento, como também para a distração e a alienação.

b) Tornaram as comunicações instantâneas, ocorrendo em tempo real, o que em um amplo espaço virtualizado possibilitou o desenvolvimento de uma dinâmica social extremamente veloz.

c) Desmaterializaram as comunicações, fazendo com que os documentos não tenham mais a necessidade de uma estrutura física, mas simplesmente uma estrutura virtual.

d) Desterritorializaram as comunicações no sentido de possuir um alcance para além do território estatal, das fronteiras geográficas, físicas ou materiais, ocorrendo em um espaço extremamente amplo, constituído em uma rede mundial de computadores.

e) Possibilitaram amplo acesso a informações e conhecimentos, permitindo maior circulação de perspectivas diferentes de informações, bem como uma grande ambivalência entre transparência e ocultação na disponibilização de dados tanto públicos como privados.

f) Tornaram mais evidente a complexidade das informações, tanto em termos de transparência como de ocultação, na medida em que as informações deixaram de ser monopólio de redes de rádio e televisão, podendo ser compartilhadas informações contraditórias por qualquer pessoa ou, da mesma forma, serem hackeadas.

Essa revolução nas comunicações ampliou extremamente a capacidade e o alcance das relações sociais no espaço-tempo, inaugurando um novo campo de conexões globais, o ciberespaço, compreendido como um "novo meio de comunicação que surge da interconexão

\footnotetext{
${ }^{11} \mathrm{O}$ que não é comunicação (social) diz respeito à dimensão biológica (física) ou à dimensão psíquica. É a comunicação um elemento de conectividade social por excelência.
} 
mundial dos computadores" (LEVY, 2007, p. 17), um ambiente virtual que conecta as infraestruturas materiais de comunicações digitais, um universo de informações e os seres humanos que o alimentam e se relacionam virtualmente. Em razão dessas conexões de redes virtuais com amplitude global, Manuel Castells passa a chamar essa forma de organização social de Sociedade da Informação ou Sociedade em Rede (CASTELLS, 2005).

Há um excesso de informações disponibilizadas na Internet. Muitas delas são falsas, a exemplo das fake news. ${ }^{12} \mathrm{~A}$ incerteza e desconfiança que se cria com isso gera uma enorme dificuldade para os processos de escolha e tomadas de decisão. A necessidade de garantir certa capacidade de seleção e gerenciamento de informações coloca em evidência a importância de desenvolver determinada forma de confiança (LUHMANN, 1996) para uma redução mais sofisticada da complexidade.

Além disso, convém mencionar que casos de violações de direitos humanos dos quais se tem conhecimento hoje podem, de fato, existir, silenciosa e invisivelmente há mais tempo e somente agora estão sendo veiculados na comunicação social. Não estar na comunicação da sociedade pode gerar a sensação de não existirem. Da mesma forma, isso cria a sensação de que possa estar havendo na atualidade um aumento de violação dos direitos humanos, quando na realidade o que está ocorrendo é somente a comunicação de algo que já existia.

Muitas dessas transformações afetam os direitos humanos, tanto de forma positiva como negativa. As Novas Tecnologias Digitais produzem um grande paradoxo de inclusão e exclusão. A revolução desencadeada nas comunicações vem ocorrendo de uma forma tão ampla que engloba a todos, quase inevitavelmente. Isto exige que aqueles que estejam à margem dessas comunicações digitais tenham de se esforçar para se adaptar, sob pena de serem excluídos. Convém dedicar especial atenção a uma forma perversa de exclusão social, que é a exclusão da comunicação. Essa exclusão pode alcançar efeitos dramáticos. Significa que para algo ou alguém ser observado na sociedade é preciso participar ou ser tematizado na comunicação social. Não basta que algo ocorra de fato, também é preciso que seja parte da realidade construída como observação e comunicação social.

Por isso, pode-se compreender que uma cultura jurídica dogmática muitas vezes contribui para a manutenção de certa invisibilidade dos problemas sociais não resolvidos pelo Direito. Além de o Direito, em algumas situações, não ser capaz de resolver problemas antigos, complexos e sistêmicos a partir de uma única decisão jurídica, sua ineficácia, morosidade e dogmatismo podem contribuir muito para a manutenção crônica de certos problemas sociais que se arrastam no tempo.

O Direito operacionaliza-se tradicionalmente com certo conservadorismo. Em alguma medida isso não significa um problema e até pode ser necessário, contudo ocorrendo de forma excessiva pode significar um obstáculo à efetividade do Direito, em especial dos direitos humanos. É preciso ter em mente que o Direito possui uma lógica de operacionalização pró-

\footnotetext{
12 São informações produzidas por notícias falsas, matérias publicadas por blogs e sites falsos, ou mesmo sistemas de computador que não só elaboram notícias falsas, mas também as disparam para uma grande quantidade de usuários de acordo com as preferências já captadas também por meio de programas muitas vezes fornecidas pelos próprios usuários mediante programas específicos para a obtenção desses dados.
} 
pria (auto-organizativa). Isso pode ser mais bem compreendido considerando a ideia de que o Direito se desenvolve basicamente a partir de duas formas de operacionalização: Programação Condicional e Programação Finalística (LUHMANN, 1985, p. 29).

Essa perspectiva dogmática revela fortes influências e traços de uma epistemologia jurídica forjada na modernidade, a partir de uma concepção de mundo estável, presente na Física de Isaac Newton, mantida na Filosofia de Immanuel Kant e posteriormente influenciando o normativismo de Hans Kelsen, principal referência do pensamento jurídico na modernidade (ROCHA, 2003a, p. 311).

Como bem menciona Rocha, o Direito a partir da programação condicional tende a acentuar o passado com o intuito de controlar o futuro (ROCHA, 2003b, p. 196). Nisso consiste a pretensão de que um determinado "passado selecionado" se repita nas tomadas de decisão futuras. Trata-se de uma estratégia de conservação das formas de comportamentos e valores que se pretende preservar no tempo e no espaço mediante a ideia de normas contrafáticas, ou seja, normas que são mantidas válidas mesmo contra eventual violação, a fim de acentuar a importância da estabilização e manutenção do Direito com longa duração (LUHMANN, 1983, p. 45).

A auto-organização precisa de um mínimo de conservação e também de certa mudança para que seja possível a necessária atualização em relação às transformações sociais. 0 problema surge quando a produção de repetição, que significa conservar o passado, é excessivamente acentuada, revelando epistemologicamente suas fragilidades, defasagens e insuficiências diante de um contexto altamente complexo e dinâmico.

A partir dessa perspectiva mais conservadora, frequentemente a complexidade social é negada por observações simplistas, reducionistas e fragmentadas que forjam uma dogmática jurídica excessivamente fechada para as influências do ambiente social. Um exemplo disso pode ser a concepção temporal do Direito diante dos avanços obtidos em outras áreas. Embora no âmbito da Física Einstein já tenha superado a perspectiva de tempo newtoniana, no Direito essa concepção temporal que foi mantida na Filosofia kantiana também influenciou Kelsen, que na atualidade ainda possui um grande peso na epistemologia jurídica. O que se pode observar é que concepções bem desenvolvidas em outras áreas parecem esbarrar numa espécie de Armadura Dogmática do Direito (FLORES; ROCHA, 2016, p. 203), que impede qualquer novo conhecimento de entrar no âmbito jurídico, a fim de evitar qualquer abalo à estabilidade conservadora dessa forma de dogmática. Assim, conhecimentos desenvolvidos em outras áreas que poderiam dar alguma contribuição para a racionalidade jurídica, sofrem forte resistência do próprio Direito quando concebido em uma perspectiva dogmática.

Se a dimensão dogmática do Direito for pensada a partir da programação condicional (LUHMANN, 1985, p. 27-28) é de se considerar que esta se mostra relevante na sua auto-organização (LUHMANN, 2016, p. 40), pois possibilita que o Direito tenha certa operacionalização. Quando se acentua excessivamente essa perspectiva, contudo, passa-se a incorrer em um arriscado conservadorismo, que pode comprometer a qualidade do Direito, sobretudo no que diz respeito à sua eficácia e realização dos direitos humanos.

Nesse sentido pode-se observar, em contraste com a dinâmica da sociedade complexa, sinais de defasagem epistemológicas do Direito. Por isso é preciso uma epistemologia jurídica sofisticada que permite saber quando o Direito precisa acentuar a estabilidade e quando deve 
promover a mudança (ROCHA, 2003b, p. 199). Do contrário, permitir a predominância de um excessivo conservadorismo, além de eventualmente contribuir para a ineficácia do Direito, também pode ser uma forma de violência aos direitos humanos. A ineficácia do Direito Corrente pode significar, direta ou indiretamente, a ineficácia dos direitos humanos. Por isso os direitos humanos devem estar implicados direta e epistemologicamente no Direito Corrente. Dessa forma, pensar a epistemologia do Direito como um todo também é uma forma de pensar a valorização dos direitos humanos. É preciso acentuar a importância da realização dos direitos humanos nos níveis mais básicos e elementares de forma progressiva, evitando em especial situações que possam significar retrocesso ao que já se conseguiu garantir (formalmente) na ordem jurídica como um todo.

Nesse sentido as Novas Tecnologias Digitais, além de permitirem a problematização de epistemologias mais conservadoras, também trazem obstáculos que são simultaneamente ótimas oportunidades para o aprimoramento do Direito. Novas situações irão exigir certa inovação do Direito, pois sendo eventualmente inéditos os problemas, podem escapar da lógica de operacionalização dogmática de buscar no passado subsídios para responder aos problemas futuros. Novas situações demandarão novas reflexões. Antigas demandas deverão ser observadas a partir de novos olhares, explorando, sobretudo, o potencial de alternativas ainda não experimentadas. A própria dinâmica do contexto, constituída por um "conjunto de técnicas (materiais e intelectuais) de práticas, de atitudes, de modos de pensamento e de valores" chamada de Cibercultura (LEVY, 2007, p. 17), constitui um espaço fértil para potenciais emancipatórios e antiemancipatórios, entre eles incontáveis violações aos direitos humanos.

Inúmeros crimes praticados por meio das redes de computadores (seja no âmbito da Web seja da Deep Web) são apenas um exemplo de certo aspecto da complexidade social que desafia a epistemologia jurídica com um volume surpreendente, com alcance inimaginável e um alto nível de incerteza reconfigurando novas práticas que também podem produzir todos os dias alguma violação aos direitos humanos.

De certa forma as Novas Tecnologias Digitais, além de possibilitarem um potencial, tanto construtivo como destrutivo, contribuem negativamente para a acentuação de um problema diário em relação aos direitos humanos: a necessidade de compreender a complexidade do contexto social e impedir violações aos direitos humanos que ocorrem diariamente, apesar de toda a legislação, nacional e internacional, já conquistada. Assim, em um âmbito geral do Direito, as conquistas formais contrastam com certa ineficácia e desrespeito aos direitos humanos.

Historicamente as conquistas de formalização dos direitos humanos em tratados, declarações ou legislações estatais, apesar de serem de grande importância, não foram suficientes para a concretização desses direitos. É fundamental certa disposição política para propor uma prática efetiva e um ponto de partida que seria uma perspectiva epistemológica adequada.

Assim, a partir de um requestionamento, como proposto por Ost (1999, p. 195), a exigência de uma revisão da epistemologia jurídica faz-se altamente necessária e urgente. Isso pode ser desenvolvido como parte dos esforços em promover a Resiliência do Direito como condição de possibilidade para o enfrentamento dos novos desafios tecnológicos e epistemológicos da Sociedade Complexa. 


\section{Resiliência do Direito e as Contribuições aos Direitos Humanos Diante dos Desafios das Novas Tecnologias Digitais}

Essa sociedade complexa observada, em especial a partir da Cibercultura, acentua o contraste entre as rápidas mudanças, imprevisibilidades, incertezas e uma forma tradicionalmente conservadora (dogmática) de operacionalizar o Direito. A partir de uma perspectiva sociológica construtivista, esse contexto revela-se um campo fértil, possibilita observar novas dificuldades e oportunidades para o aprimoramento do Direito, considerando principalmente a importância da mudança e atualização, algo imprescindível para sustentar a pretensão de elaborar decisões jurídicas que alcancem certo nível de satisfação, tanto do ponto de vista temporal quanto epistemológico e organizacional (LUHMANN, 2007, p. 481).

Pensar o Direito imerso em um contexto complexo e dinâmico exige a necessidade de desenvolver a capacidade de renovação, sem desconsiderar a importância de uma concepção de "conservação" (OST, 1999, p. 52). Para tanto é fundamental o enfrentamento dos obstáculos (BACHELARD, 2011, p. 17) contemporâneos, multifacetados, tanto internos (epistemologia jurídica conservadora), como externos (ambiente social). Na medida em que a conjuntura social exige maior abertura para enfrentar os novos desafios, as posturas jurídicas mais conservadoras apresentam resistência a qualquer mudança que possa comprometer os espaços de controle dogmático do sentido jurídico.

Para superar a resistência da dogmática jurídica e poder responder adequadamente à complexidade do mundo, o Direito precisa ser resiliente. A ideia de resiliência teve origem no âmbito da Física ${ }^{13}$ ou Engenharia de Materiais, indicando a propriedade de determinado material que permite suportar certa tensão e posteriormente retornar ao estado anterior sem sofrer eventual efeito danoso. Na Psicologia ${ }^{14}$ significou a capacidade de um ser humano enfrentar situações difíceis e posteriormente recuperar certo equilíbrio sem assimilar a experiência como trauma. Em ambos os casos pode-se constatar que a resiliência sugere a capacidade para enfrentar obstáculos, se reorganizando de forma que a superação também corresponda à obtenção de aprendizado (TAVARES, 2001, p. 52).

Da mesma forma, a resiliência ${ }^{15}$ foi ressignificada no âmbito jurídico, sugerindo certa capacidade de superação, aprimoramento e inovação do Direito (FLORES; ROCHA, 2016, p. 102-103). Surge com isso a concepção de resiliência do Direito que basicamente indica uma

\footnotetext{
${ }^{13}$ No âmbito da Física, resiliência é compreendida como a habilidade de uma substância retornar a sua forma original depois de ter sido submetida a uma pressão e após esta ser removida, ou seja, sua flexibilidade, que é calculada a partir de fórmulas matemáticas (PINHEIRO, 2004).

${ }^{14}$ No âmbito da Psicologia a resiliência pode ser compreendida como a capacidade de um ser humano se adaptar e se recuperar psicologicamente quando é submetido a alguma adversidade na vida, no esforço para superá-la (PINHEIRO, 2004). Essa transposição tornou-se possível na medida em que se considera que "a relação tensão/pressão com deformação não permanente do material corresponderia à relação situação de risco/estresse/experiências adversas com respostas finais de adaptação/ajustamento no indivíduo" (YUNES; SZYMANSKI, 2001, p. 16).

${ }^{15}$ Tavares "discute a origem do termo sob três pontos de vista: o físico, o médico e o psicológico. No primeiro, a resiliência é a qualidade de resistência de um material ao choque, à tensão, à pressão, a qual lhe permite voltar, sempre que é forçado ou violentado, à sua forma ou posição inicial - por exemplo, uma barra de ferro, uma mola, elástico, etc. No segundo, a resiliência seria a capacidade de um sujeito resistir a uma doença, a uma infeç̧ão, a uma intervenção, por si próprio ou com a ajuda de medicamentos. E, no terceiro, a resiliência também é uma capacidade de as pessoas, individualmente ou em grupo, resistirem a situações adversas sem perder o seu equilíbrio inicial, isto é, a capacidade de se acomodar e reequilibrar constantemente" (2001, p. 52).
} 
capacidade operacional, epistemológica e comunicacional para enfrentar obstáculos (internos e externos), fazendo com que o processo de tomada de decisão jurídica seja altamente efetivo como um momento de permanente requestionamento num processo de construção evolutiva. Simbolicamente ela dá os contornos do desenvolvimento de condições necessárias para o enfrentamento de adversidades (complexidade), com certa disposição para um aprendizado transformador do Sistema do Direito, ${ }^{16}$ a partir da melhor capacidade de adaptação e readaptação dinâmica (PINHEIRO, 2004, p. 67-75). Assim, a resiliência do Direito consiste num potencial criativo e inovador do Direito de enfrentar os desafios da sociedade atual, sendo capaz de se reorganizar, aprender e se atualizar de forma construtiva, a fim de apresentar respostas mais satisfatórias aos problemas contemporâneos.

Ao pressupor uma epistemologia reflexiva, a resiliência do Direito permite que se gerencie a produção de condições para a mudança evolutiva nas próprias estruturas e comunicação do Direito, a fim de desenvolver o potencial para a produção de ressonâncias efetivas, como elementos ou alternativas de soluções aos problemas sociais.

Essa é uma forma de pensar certa capacidade de aprimoramento constante, a partir de uma observação diferenciada que permite se ajustar criativamente às situações inéditas e imprevisíveis, acentuando a mudança e inovação como forma para a superação reflexiva dos obstáculos e possibilitando o aprendizado do sistema jurídico (FLORES; ROCHA, 2016, p. 96).

Por meio dessa estratégia o Direito também pode se operacionalizar de forma construtivista e sistêmica, buscando obter o máximo de ganhos evolutivos nos mais diversos aspectos, bem como utilizando esse aprendizado para promover novos e constantes aprimoramentos, tanto em suas estruturas internas como em suas ressonâncias na sociedade.

Isso tudo é possível na medida em que a resiliência do Direito visa a criar de forma democrática e transparente as condições mais elevadas de sofisticação para os processos de tomada de decisão jurídica (FLORES; ROCHA, 2016, p. 219), ${ }^{17}$ a partir da existência de espaços dialógicos e transdisciplinares de observação (MORIN, 2002, p. 64).

As violações de direitos humanos em todo o mundo constituem parte dos problemas que emergem da complexidade social. Apesar de inúmeros avanços formais em termos de debates, tratados e legislações construídos para promover a realização dos direitos humanos, ainda persistem problemas antigos não resolvidos (SOUZA DE LOBO; KRETSCHANN, 2003, p. 118-119), problemas antigos reconfigurados a partir da Cibercultura e mais recentemente novos problemas a partir situações até então inéditas que emergem de uma sociedade em constante transformação.

\footnotetext{
${ }^{16}$ Convém mencionar que, segue-se aqui uma tendência de mudança na epistemologia contemporânea, de uma perspectiva analítica para uma perspectiva mais pragmática, sem desconsiderar conjuntamente outras perspectivas (as três dimensões da linguagem: sintaxe, semântica e pragmática). Isso indica que não se tem como principal preocupação a construção de conceitos e classificações. Seja em razão de suscitarem controvérsias intermináveis, ou por servirem ideologicamente como espaço a ser preenchido por interpretações arbitrárias, enganando, às vezes por insuficiência ou conveniência, a complexidade da sociedade contemporânea (ROCHA, 2003b, p. 93).

17 O processo democrático e transparente significa uma forma de evitar as manipulações arbitrárias, uma vez que diante de um espaço democrático de alternativas expostas de forma transparente, ficaria mais difícil optar por uma alternativa que interesse a poucos, tendo opções melhores conhecidas de todos (ROCHA, 2016, p. 217).
} 
Enfrentar os obstáculos aos direitos humanos na atualidade exige algumas posturas diferentes para se obter resultados de sua efetivação ainda não alcançados. O desafio de compreender os direitos humanos e superar seus obstáculos em um contexto hipercomplexo não permite que se utilize racionalidades lineares e muito menos lógicas binárias simplistas que acabam em dualismos ingênuos. Paradoxalmente a violação dos direitos humanos reforça a sua importância (MAGALHÃES, 2010, p. 47), contudo é preciso compreendê-los em novos contornos da complexidade (Novas Tecnologias Digitais), buscando sempre reforçar sua valorização e reestabilização na sociedade. Nesse sentido, muitas das novas configurações das relações sociais ganham contornos incertos, e os direitos humanos podem significar possibilidade de aberturas, de buscar abrir fissuras na Dogmática Jurídica, predominantemente fechada (DE GIORGI, 2017, p. 328).

A partir de um Direito resiliente se pressupõe uma observação complexa dos obstáculos que possam existir em relação à proteção, garantia e realização dos direitos humanos. Nesse processo de compreender as peculiaridades dos problemas sociais na atualidade, a pesquisa empírica de caráter sociológico, como parte de uma operacionalização resiliente do Direito, ganha especial importância. Funciona como uma forma de obter um diagnóstico aprofundado sobre os motivos de eventuais ineficácias de decisões jurídico-políticas que deveriam contribuir ou promover a realização dos direitos humanos.

O Direito tem maiores condições de ser resiliente quando se consegue maximizar o desenvolvimento de conhecimento de ponta, por meio de pesquisas sociológicas e transdisciplinares, compartilhadas democraticamente para dar suporte aos processos de tomada de decisão jurídica. Isso indica a importância de novos espaços para uma maior aproximação entre universidades e tribunais, bem como um maior desenvolvimento da carreira de pesquisador no âmbito jurídico.

Para tanto, os espaços de observação reflexiva transdisciplinares (NICOLESCU, 2005, p. 57) são de grande importância para incrementar as estruturas internas do sistema do Direito e consequentemente possibilitar um potencial de inovação que possa levá-lo a apresentar respostas diferentes aos problemas de respeito aos direitos humanos ainda não solucionados, considerando o pluralismo de perspectivas na observação (TEUBNER, 2005, p. 87).

A partir dessa perspectiva, dever-se-ia permanentemente buscar respostas consistentes sobre as insuficiências dos direitos humanos e o que se poderia fazer para a superação de problemas que ainda persistem. O que é necessário para se evoluir constantemente na garantia, proteção e realização dos direitos humanos? Para essa pergunta já se pode pressupor que não se trata de uma única decisão ou medida. É preciso que a mudança seja desencadeada de forma sistêmica. Para tanto é preciso ressignificar a importância da mudança no Direito, sem desconsiderar também a relevância da noção de estabilidade.

Não se trata de sustentar simplesmente que o Direito deve ser flexível e se abrir para o novo, ou que deva mudar de qualquer forma, pois está numa sociedade que muda constantemente. Ser resiliente não significa apenas ser flexível, é mais do que isso. ${ }^{18} \mathrm{Um}$ Direito resiliente pressupõe conservar o que já foi conquistado no passado (direitos humanos), produzin-

\footnotetext{
${ }^{18}$ A flexibilidade pode ser importante se articulada de forma resiliente e construtiva, mas por outro lado, também pode servir para manipulações mediante mudanças irresponsáveis (TAVARES, 2001).
} 


\section{Humanos e}

Democracia

do repetição, sem incorrer em um excessivo conservadorismo. Produz mudança (diferença) abrindo a possibilidade para perspectivas inovadoras, sem incorrer, contudo, em elaborações levianas e irresponsáveis. O que garante manter e não exceder certos limites são processos construtivos de reflexões dialógicas, transparentes e democráticas, pautadas por "conhecimentos de ponta"19 (FLORES; ROCHA, 2016, p. 110).

Os direitos humanos permitem a observação dessa necessária repetição, pois são direitos que precisam ser repetidos, valendo-se da importância da programação condicional (do Direito) que acentua certa conservação de um passado de conquistas de direitos elementares aos seres humanos (LUHMANN, 1985, p. 27-28). Não se pode, contudo, desconsiderar também a importância da programação ${ }^{20}$ finalística (ROCHA, 2003b, p. 196). Nesse sentido, os direitos humanos permitem observar a importância da resiliência para equacionar a produção de repetição (estabilização) e diferença (mudança) na operacionalização jurídica, a fim de promover uma atualização resiliente do Direito como um todo. Isso porque uma decisão que acentue alguma mudança precisa encontrar uma motivação e fundamentação consistente. Essa equação resiliente de conservação e mudança nas operações do Direito revela o caráter reflexivo na epistemologia jurídica, que operacionaliza o paradoxo de um Direito que é fechado e aberto simultaneamente (TEUBNER, 1989).

Por isso um Direito resiliente de caráter reflexivo permite desenvolver a disposição e capacidade de pensar o que normalmente e tradicionalmente não é pensado (complexidade social). É um Direito com certa disposição para se operacionalizar diante da imprevisibilidade e incerteza. Para tanto, também busca o constante aprimoramento de suas estruturas internas. Isso resultará em ganhos evolutivos que no futuro permitirão ao sistema do Direito abrir-se para o novo (FLORES; ROCHA, 2016, p. 96).

Nesse sentido, a resiliência do Direito (epistemológica, organizacional e comunicacional) permite melhores condições para enfrentar os desafios da realização dos direitos humanos diante da complexidade social contemporânea. A resiliência do Direito significa uma potencialidade fundamental para a realização dos direitos humanos, porque busca: 1) Epistemologicamente uma forma de observação e reflexão jurídica com a complexidade contemporânea como sendo de fundamental importância para superar os obstáculos epistemológicos (internos) sustentados por uma dogmática jurídica que ao produzir certo nível de ineficácia, estende esse efeito à realização dos direitos humanos nas dimensões mais elementares do universo jurídico; 2) Operacionalmente busca otimizar e aprimorar resilientemente o potencial das organizações tanto para gerenciar uma grande quantidade de informações relevantes como para criar espaços transdisciplinares, por meio dos quais os conhecimentos de ponta desenvolvidos por universidades possam ser democraticamente compartilhados a fim de ser-

\footnotetext{
${ }^{19}$ A concepção de "conhecimento de ponta" significa os conhecimentos mais evoluídos tanto do ponto de vista teórico como em relação aos processos e procedimentos de sua efetivação, considerando uma perspectiva inter e transdisciplinar. Significa buscar compartilhar o desenvolvimento do conhecimento com a multiplicidade de áreas de saber e suas respectivas pesquisas que também possam servir socialmente de forma transdisciplinar.

${ }^{20}$ Nesse sentido, Rocha traz à tona a pertinente observação sobre o processo de tomada de decisão, que em relação ao tempo pode ocorrer de duas maneiras. Uma decisão pode ser tomada de acordo com uma programação condicional, entendendo, assim, uma decisão voltada ao passado, que nega a produção de tempo, enfatizando a repetição. Ou de outra forma, uma decisão pode ser tomada segundo uma programação finalista, produzindo tempo que, por sua vez, significa a produção de diferença (ROCHA, 2003b, p. 196).
} 
vir de elemento de solução para dar suporte e aprimorar os processos de tomadas de decisão jurídicas em prol da efetivação dos direitos humanos. 3) Comunicacionalmente busca fazer com que todo o processo jurídico seja reflexivo, procurando aprimorar tanto as operações internas quanto a capacidade de alcançar eficácia nas suas comunicações com o ambiente social, ou seja, potencializando as possibilidades de o Direito produzir um resultado mais eficaz na sociedade e consequentemente respostas mais satisfatórias à solução dos direitos humanos na atualidade.

Isso tudo pressupõe condições epistemológicas e operacionais para pensar a inovação do Direito. Mais do que desenvolver conhecimentos teóricos sobre os direitos humanos, assinar tratados e publicar legislações, é preciso que os estes aconteçam efetivamente na atualidade. Para tanto é necessário que o sistema do Direito possua uma estratégia de observação por meio de pesquisas empíricas construtivistas, a fim de diagnosticar os obstáculos existentes no contexto atual que dificultam a plena realização do Direito, bem como os pontos a serem enfrentados de forma sistêmica na sociedade. Isso é possível nas perspectivas de um Direito resiliente, que permite a observação dos direitos humanos como novos espaços interpretativos, mediante os quais se pode vislumbrar alternativas diferentes ainda não suficientemente experimentadas (DE GIORGI, 2017, p. 329).

\section{Conclusão}

A sociedade atual caracteriza-se por um ambiente altamente complexo. O desenvolvimento das Novas Tecnologias Digitais possibilitou o surgimento de novos espaços de interação, repletos de imprevisibilidade e incertezas. Esse novo contexto ganha uma dimensão virtual a partir do ciberespaço e uma dinâmica com novos contornos a partir Cibercultura. As novas possibilidades de comunicações desencadearam uma incrível desterritorialização e uma dinâmica temporal extremamente veloz. Esse conjunto de múltiplas transformações criou um cenário simultaneamente difícil e fértil para compreender a complexidade social contemporânea. Assim a complexidade da sociedade, que é potencializada pelo desenvolvimento das Novas Tecnologias Digitais, coloca em evidência as insuficiências conservadoras do Direito diante do contexto atual. Essa dinâmica social e tecnológica que apresenta um grande potencial de influência social, tanto destrutivo quanto destrutivo dos direitos humanos, também problematiza profundamente a epistemologia jurídica de caráter mais tradicional.

O grande problema que surge com a constante expansão da complexidade e tecnologia é o contraste entre um Direito predominantemente dogmático e uma sociedade que parece estar cada vez mais dinâmica e contingente. Assim as insuficiências e fragilidades da dogmática jurídica são colocadas em evidência e podem ser observadas, basicamente, de duas maneiras: Uma trata-se de ver uma epistemologia reducionista e conservadora que sacrifica a complexidade em prol de certa operacionalização excessiva simplificada. A outra versa sobre uma simplificação manipulada racionalmente como parte de uma estratégia formal para dar manutenção a certo controle na produção de sentido jurídico (em decisões jurídicas). Ambas as perspectivas são expressões da dogmática jurídica, que pressupõe uma maneira altamente conservadora de pensar e operacionalizar o Direito, provocando um problema epistemológico generalizado, que dificulta a produção de respostas satisfatórias a uma sociedade complexa. Uma postura que parece transportar certo conformismo e comodismo com uma produção 
jurídica voltada a afastar radicalmente qualquer crítica que coloque em risco a manipulável estabilidade da dogmática jurídica. Por isso que na perspectiva da dogmática jurídica insiste-se em considerar o mundo mais simples do que ele de fato se apresenta. ${ }^{21} \mathrm{~A}$ necessidade de realizar alguns ajustes no Direito quando a dogmática jurídica contrasta com a sociedade complexa, revela-se como uma grande dificuldade para um Direito ancorado em pressupostos conservadores da modernidade.

Uma forma de enfrentar os desafios da sociedade complexa, considerando as tendências da Cibercultura, é levar em conta a importância de aprimorar a capacidade de observação no Direito. Isso pressupõe uma revisão epistemológica e consequentemente novas condições para melhor compreender (ou construir) a realidade contemporânea.

Para que se possa melhor compreender o contexto social a partir do Direito, considerando a complexidade atual e objetivando se aprimorar para apresentar respostas cada vez mais satisfatórias aos problemas sociais, é preciso que o Direito: a) consiga desenvolver uma observação que contemple em seu horizonte o máximo possível de aspectos da complexidade social; b) consiga romper com seus próprios obstáculos epistemológicos internos, no sentido de ser capaz de transgredir sua própria armadura dogmática, a fim de buscar alternativas de solução que ainda não foram tentadas; c) busque certa sofisticação que lhe permita acentuar a programação finalística (diferença) de forma a desencadear um aprendizado no próprio sistema jurídico; d) retome sua estabilização de forma aprimorada, acentuando a importância de pensar simultaneamente a elaboração de suas decisões para problemas sociais, e também o próprio processo evolutivo do Direito.

Nesse sentido, a resiliência que é ressignificada no âmbito jurídico, no que diz respeito à sua dimensão epistemológica, organizacional e comunicacional, da origem à concepção de resiliência do Direito e se mostra de grande relevância para as reflexões e operacionalizações jurídicas.

Enquanto um potencial inovador do Direito, que pressupõe a capacidade de enfrentar desafios, de se reorganizar, de se aprimorar, de se atualizar e de inovar a fim de apresentar uma resposta mais satisfatória ao contexto social, a resiliência do Direito é uma condição fundamental para pensar os direitos humanos diante dos desafios trazidos pelo avanço das Novas Tecnologias Digitais.

A resiliência do Direito significa uma nova perspectiva de observação e ao mesmo tempo um potencial de produção de diferença, aprendizado e inovação do Direito, a fim de se ter mais eficácia e produzir respostas mais satisfatórias às demandas sociais, mostrando-se resiliente diante dos desafios das transformações da sociedade contemporânea. É em razão dessa disposição para produzir diferença explorando perspectivas ainda não experimentadas que a resiliência do Direito é necessária para pensar os direitos humanos na sociedade atual.

\footnotetext{
${ }^{21}$ Isso indica certa permanência de uma racionalidade moderna, que pressupõe uma observação excessivamente conservadora, impedindo o acesso pleno à complexidade.
} 
Muitos problemas que impedem a efetivação dos direitos humanos não são de difícil solução teórica, contudo torna-se altamente complexo observar a configuração da sua inefetividade, ou seja, os motivos pelos quais os direitos humanos ainda são violados, e desenvolver uma estratégia que possa desencadear sistemicamente estímulos voltados a contribuir para a sua realização.

A resiliência do Direito pressupõe uma epistemologia que permite certa abertura construtivista, tanto para diagnosticar a complexidade da ineficácia dos direitos humanos na atualidade, como para repensar a capacidade de decidir de forma diferente. Consequentemente isso pode significar um processo contínuo de aprendizado e maiores possibilidades de se apresentar respostas inovadoras a problemas novos e antigos ainda não solucionados. Esse maior potencial para enfrentar a complexidade também conta com um processo mais democrático para desenvolver espaços de observação e reflexões transdisciplinares compartilhados que possam auxiliar ou dar suporte aos processos de tomada de decisão jurídica (FLORES; ROCHA, 2016, p. 2.017). Nesse sentido, o Direito deve ser resiliente na realização dos direitos humanos, devendo buscar desenvolver uma observação sofisticada tanto no nível epistemológico quanto no organizacional. Isso permite identificar os obstáculos, tanto internos como externos, à realização dos direitos humanos nos níveis mais elementares da ordem jurídica.

Por isso, desenvolver a resiliência do Direito é uma ótima estratégia para pensar a realização dos direitos humanos na sociedade contemporânea. Num primeiro momento essa capacidade pressupõe uma epistemologia aberta à complexidade. Isso possibilita, além da superação de obstáculos epistemológicos, também uma observação mais aprofundada da conjuntura sistêmica de obstáculos que impedem a realização dos direitos humanos. Do ponto de vista operacional, a resiliência possibilita pensar a otimização e aprimoramento do potencial das organizações. Uma grande quantidade de informações relevantes pode ser gerenciada conjuntamente com espaços transdisciplinares. As organizações podem comportar espaços de produção de conhecimentos de ponta, desenvolvidos por universidades e democraticamente compartilhados a fim de servir de elementos de solução para dar suporte e aprimorar os processos de tomadas de decisão jurídicas em prol da realização dos direitos humanos. A resiliência também deve atravessar o aspecto comunicacional, como uma capacidade de aprimorar o potencial de eficácia das comunicações a fim de pensar resultados mais satisfatórios na realização dos direitos humanos em meio a uma conjuntura sistêmica e complexa da sociedade contemporânea. É preciso compreender tanto as potencialidades de problemas como de soluções numa perspectiva sistêmica e comunicacional. Isso é possível sob o ponto de vista de um Direito resiliente, que permite a observação dos direitos humanos de forma sistêmica e comunicacional, como novos espaços interpretativos, por meio dos quais é possível vislumbrar alternativas diferentes, ainda não suficientemente experimentadas (DE GIORGI, 2017, p. 329).

\section{Referências}

BACHELARD, Gaston. La formation de l'esprit scientifique: contribuition a une psycaalyse de la connaissance. Paris: Librairie Philosophique J. Vrin, 2011.

BARONNE, Dante Augusto; BOESING, Ivan Jorge (Org.). Inteligência artificial: diálogos entre mentes e máquinas. Porto Alegre: AGE, 2015.

CASTELLS, Manuel. A sociedade em rede. Tradução Roneide Venancio Majer. 8. ed. São Paulo: Paz e Terra, 2005. CLAM, Jean. Questões fundamentais de uma teoria da sociedade: contingência, paradoxo, só-efetuação. São Leopoldo: Ed. Unisinos, 2006. 


\section{Humanos e}

Pireitos

Democracia

CORSI, Giancarlo; BARALDI, Cláudio; ESPÓSITO, Elena. Glosario sobre la teoría social de Niklas Luhmann. Tradução Miguel Romero Pérez y Carlos Villalobos. Universidad Iberoamericana. Guadalajara, México: Diseño y Letras, 1996.

DE GIORGI, Raffaele. Por uma ecologia dos direitos humanos. In: Revista Opinião Jurídica, Fortaleza, ano 15, n. 20, p. 324-340, jan./jun. 2017. Disponível em: <http://periodicos.unichristus.edu.br/index.php/opiniaojuridica/ article/view/1506/468>. Acesso em: 24 jun. 2018.

FERRAZ JR., Tercio Sampaio. Introdução ao estudo do Direito: técnica, decisão, dominação. São Paulo: Atlas, 2011.

FLORES, Luís Gustavo Gomes; ROCHA, Leonel Severo. Resiliência do Direito. Curitiba: Prismas, 2016.

FOERSTER, Heinz von. Visão e conhecimento: disfunções de segunda ordem. In: SCHNITMANN, Dora Fried (Org.). Novos paradigmas, cultura e subjetividade. Tradução Jussara Haubert Rodrigues. Porto Alegre: Artes Médicas, 1996.

JANELA DA ALMA. Direção: João Jardim e Walter Carvalho. Produtor: João Jardim. Produtoras: Ravina Films e Dueto Films. 22, out. 2001, DVD (73min.).

LEVY, Pierre. Cibercultura. Tradução Carlos Irineu da Costa. 2. ed. São Paulo: Ed. 34, 2007.

LUHMANN, Niklas. El Derecho de la Sociedad. Tradução Javier Torres Nafarrate. México: Universidad Iberoamericana, 2002. (Colección Teoría Social).

. Sistemas sociais: esboço de uma teoria geral. Petrópolis: Vozes, 2016.

La sociedad de la sociedad. México: Herder, 2007.

Confianza. Barcelona, España: Anthropos; México: Universidad Iberoamericana; Santiago de Chile: Insti-

tuto de Sociología; Pontificia Universidad Católica de Chile, 1996.

Sociologia do Direito I. Tradução Gustavo Bayer. Rio de Janeiro: Tempo Brasileiro, 1983.

Sociologia do Direito II. Tradução Gustavo Bayer. Rio de Janeiro: Tempo Brasileiro, 1985.

A realidade dos meios de comunicação. Trad. Ciro Marcondes Filho. São Paulo: Paulus, 2005.

MAGALHÃES, Juliana Neuenschwander. O paradoxo dos direitos humanos. Revista da Faculdade de Direito UFPR, Curitiba, n. 52, p. 31-48, 2010. Disponível em: <https://revistas.ufpr.br/direito/article/view/30694>. Acesso em: 7 nov. 2018.

MATURANA, Humberto R.; VARELA, Francisco J. A árvore do conhecimento: as bases biológicas da compreensão humana. São Paulo: Palas Athena, 2001.

De máquinas e seres vivos: autopoiese - a organização do vivo. 3 ed. Trad. Juan Acuña Llorens. Porto Alegre: Artes Médicas, 1997.

MATURANA, Humberto. O que se observa depende do observador. In: THOMPSON, W. I. (Org.). Gaia: uma teoria do conhecimento. São Paulo: Editora Gaia, 2000, p. 61.

MORIN, Edgar. Educação e complexidade: os sete saberes e outros ensaios. Tradução Edgard de Assis Carvalho. São Paulo: Cortez, 2002.

NICOLESCU, Basarab. O manifesto da transdisciplinaridade. São Paulo: Triom, 2005.

OST, François. O Tempo do Direito. Lisboa: Instituto Piaget, 1999.

PINHEIRO, Débora Patrícia Nemer. A resiliência em discussão. Psicologia em Estudo, Maringá: Universidade Estadual de Maringá, v. 9, n. 1, p. 67-75, 2004. Disponível em: <http://www.scielo.br/scielo.php?script=sci_arttext\&pid=S1413-73722004000100009>. Acesso em: 29 set. 2008.

ROCHA, Leonel Severo. A construção do tempo pelo direito. In: ROCHA, Leonel Severo; STRECK, Lênio Luiz. Anuário do Programa de Pós-Graduação em Direito, Mestrado e Doutorado. São Leopoldo: Unidade Ciências Jurídicas, 2003a.

Epistemologia jurídica e democracia. 2. ed. São Leopoldo: Ed. Unisinos, 2003b.

SOUZA DE LOBO, lelbo Marcus; KRETSCHANN, Ângela. A universalidade dos direitos humanos no discurso internacional: o debate continua. In: ROCHA, Leonel Severo; STRECK, Lenio Luiz. Anuário do Programa de Pós-Graduação em Direito: Mestrado e Doutorado, Anuário/2003. São Leopoldo: Unisinos, 2003, p. 117-142.

TAVARES, José. A resiliência na sociedade emergente. In: TAVARES, José (Org.). Resiliência e educação. São Paulo: Cortez, 2001.

TEUBNER, Gunther. Direito, Sistema e Policontexturalidade. Piracicaba: Unimep, 2005.

O Direito como Sistema Autopoiético. Trad. José Engracia Antunes. Lisboa: Fundação Calouste Gulbenkian, 1989.

YUNES, Maria Angela Mattar; SZYMANSKI, Heloísa. Resiliência: noção, conceitos afins e considerações críticas. In: TAVARES, José (Org.). Resiliência e educação. São Paulo: Cortez, 2001. 